\title{
Análisis global de las nuevas relaciones estado/ciudadano en el marco del neoliberalismo político del siglo XXI

\author{
Hugo Jose Castro Valdebenito*
}

\begin{abstract}
Resumen
Las discusiones a nivel académico, a propósito de la evolución contemporánea de los conceptos de ciudadano y ciudadanía, han puesto en evidencia la necesidad de adecuarlos a la realidad actual de las relaciones internacionales. El quiebre del estado-nación, enmarcado en un proceso de institucionalización neoliberal, ha generado una crisis de representación y legitimidad política, que afecta directamente las relaciones entre el ciudadano y el estadonación. Por otro lado, el aumento del fenómeno migratorio sur-norte, y los avances en el reconocimiento jurídico de las ciudadanías múltiples por parte de algunos países, hacen necesario realizar una reconceptualización de las nuevas relaciones estado/ciudadano en el siglo XXI.
\end{abstract}

En este artículo plantea desde un análisis sistémico la importancia del fenómeno migratorio en la formación de la sociedad civil internacional, rompiendo la tradicional relación de vinculación jurídico/territorial entre el ciudadano y el estado-nación. El principal eje metodológico de este estudio está dado por la comparación histórica en el desarrollo de concepto contemporáneo de ciudadanía, y su relación con la migración, en la creación y conceptualización de un nuevo trato ciudadano/ estado, de carácter global y desterritorializado.

\section{Palabras clave}

Ciudadanía; migración; globalización; sociedad civil internacional; estado-nación.

\section{TITLE}

Global analysis of new relations state/citizen under the political neoliberalism of the XXI ${ }^{\text {st }}$ century

\section{Abstract}

The academic level discussions regarding the evolution of the contemporary concepts of citizen and citizenship have highlighted the need to adapt them to the current reality of international relations. The breakdown of the nation-state, framed in a process of neoliberal institutionalization, has generated a crisis of representation and political legitimacy, which directly affects the relations between the citizen and the nation-state. On the other hand, the increase of south-north migrations and the progress in the legal recognition of multiple citizenships on behalf of some countries, make it necessary to reconceptualize the new state/citizen relations in the 21st century.

This article exhibits from a systemic analysis the importance of the migratory phenomenon in the formation of the international civic society, breaking the traditional relationship linking land/ territory between the citizen and the nation-state. The main methodological focus of this study is the historical comparison in the development of a contemporary concept of citizenship, and its relation to migration, in the creation and conceptualization of a new citizen/state treatment, of a global and deterritorialized nature.
*Hugo Jose CASTRO VALDEBE-

NITO, Profesor de Historia y Geografía, Licenciado en Historia y Licenciado en Educación. Magister en Relaciones Internacionales como becario del Programa de Formacion de Capital Humano Avanzado de la Comisión Nacional de Investigacion, Ciencia y tecnología de Chile (CONICYT) en el Centro de Estudios y Asistencia Legislativa de la Pontificia Universidad Catolica de Valparaíso. Chile. Actualmente se desempeña como académico del Departamento de Historia de la Universidad de Playa Ancha, en las asiganturas de Historia de America e Historia de la Integracion. Es Editor responsable de la Revista Chilena de Relaciones Internacionales y Director Ejecutivo de la Sociedad de Historia de Valparaiso.

\section{Recibido:}

2016-11-04

Aceptado:

2017-02-22

DOI: $10.15366 /$ relacionesinternacio nales2017.35.001

\section{KEYWORDS}

Citizenship; migration; globalization; international civic society, nation-state. 


\section{ntroducción}

Los cambios institucionales a nivel global, luego de la desintegración de la Unión Soviética, han puesto en cuestión la legitimidad y la naturaleza del concepto de estado-nación, y por ende ha sido menester cuestionar y revisar el significado del concepto de ciudadanía. Entre los cambios más importantes, que el estado moderno ha profundizado en materia de ciudadanía y desde un enfoque prominentemente jurídico, está la garantía estatal entregada a todos los habitantes de un determinado territorio, para desarrollarse en un marco de seguridad y justicia, haciendo pleno uso de sus derechos políticos y sociales. Ahora bien, este esfuerzo político del estado-nación, debe entenderse a la luz de los cambios en las relaciones internacionales, a través de la globalización y la mundialización de los mercados, situación en la cual los estados-nación, pasan a ceder una parte de su soberanía nominal, en virtud de un posicionamiento global, que a fin de cuentas les produce cierta estabilidad en medio del problema de la institucionalización neoliberal. Esto no nos debe extrañar, toda vez que, a partir de los grandes desplazamientos demográficos del siglo XX, el fenómeno del ciudadano global, ha aumentado en proporciones nunca antes observadas. El fenómeno migratorio actual, es una de esas coyunturas, que nos obliga a reflexionar respecto la necesidad de conceptualizar una nueva relación entre los estados-nación y los actuales ciudadanos globales ${ }^{1}$.

A su vez, el problema de la crisis de representación y legitimidad de la democracia occidental está en auge. Por dicha razón, es importante atender a estos y otros nuevos elementos, que necesariamente nos serán útiles para abordar la problemática de una nueva relación entre el estado-nación y el ciudadano actual, enmarcado este último, en el contexto de imparables movimientos demográficos ${ }^{2}$. Debemos señalar, que en cuanto al trato o nuevo trato, que aplica el neoliberalismo político en las relaciones estado-ciudadano, es imperativo abordar también los conceptos de exclusión e inclusión, con el objeto de comprender las múltiples interacciones de este nuevo trato.

El principal objeto de este trabajo, es vincular de forma efectiva y teórica, los diferentes factores involucrados en la elaboración de nuevas relaciones y formas de vinculación entre los ciudadanos y los estados-nación. Para ello, analizaremos el concepto de ciudadano global, lo contextualizaremos en relación al fenómeno migratorio y las políticas de algunos estados, en cuanto a la utilización y fragmentación de derechos políticos y sociales, así como, la protección/seguridad y el acceso a la justicia. Tomando desde luego, algunos ejemplos de desarrollo local y sus reconocimientos internacionales. Todo esto, para explicar las nuevas estrategias de la política neoliberal en relación al concepto de ciudadano.

En la segunda parte, observaremos analíticamente como los conceptos de inclusión y exclusión, adosados a la desigualdad social, son argumentos válidos, a la luz de la teoría política y las relaciones o vínculos jurídicos preexistentes, para explicar la metodología practicada en la creación del ciudadano global y la sociedad civil internacional, a propósito del fenómeno migratorio sur-norte.

Finalmente, el estudio se detendrá para reflexionar sobre las proyecciones de este

1 LAVOLPE, Francisco, "Las nuevas ciudadanías de la globalización" en Hologramática, vol. 8, nº 6, 2008 , p. 49.

2 AGUILÓ, Antoni Jesús, "Globalización neoliberal, ciudadanía y democracia. Reflexiones críticas desde la teoría política de Boaventura de Sousa Santos" en Revista Crítica de Ciencias Sociales y Jurídicas, vol. 20, nº 4, 2008, p. 153. 
nuevo trato. Un nuevo trato, donde el estado-nación neoliberal de democracia occidental fragmentada y debilitada en lo representacional, ha condicionado una nueva forma de relación entre los habitantes del territorio y los estados soberanos.

\section{Evolucionando hacia un concepto global de ciudadano y ciudadanía.}

Históricamente, los conceptos de ciudadanía y ciudadano han evolucionado conforme la humanidad se ha organizado políticamente. Usualmente, se afirma que estos conceptos, se originan en el siglo V a.C., en la Grecia clásica, sin embrago, siglos antes ya se habían iniciado procesos democratizadores en algunas colonias helenas mediterráneas ${ }^{3}$. En dicho contexto, algunas figuras cono Pericles o Efialtes, fueron fundamentales, toda vez que lograron abrir las puertas de la vida política y por ende la participación en las instancias decisorias a hombres de diferentes extracciones sociales, coartando, en cierta media, los privilegios de la aristocracia ateniense. En Roma, en cambio, el concepto de ciudadano fue tomado y ampliado, con una importante variable, pues en su aplicación, la democracia fue fundamentalmente representativa, a diferencia de la conceptualización griega, de una democracia directa, y basada principalmente en la participación del ciudadano en la comunidad, es decir, en la Polis. No así, en el modelo romano, pues al ser representativo, el ciudadano, ya no es el que participa en la comunidad, sino en que tiene garantizado ciertos derechos, que actúa de acuerdo con la ley y que tiene la certeza que está le protegerá. No es un miembro de la polis, sino un ciudadano del Imperio ${ }^{4}$.

Siglos después de la caída del Imperio Romano, el concepto de ciudadano pierde progresivamente su naturaleza clásica greco-romana, entendida como la pertenencia a una comunidad, la del ciudadano-súbdito. Así, en el medio evo, el concepto de ciudadano, se transforma a la idea de una vinculación personal, regida por una relación de poder, más que una vinculación territorial. En dicho periodo de la historia, el concepto de ciudadanía reside en la subordinación política a un señor feudal o a un monarca y no en la idea de participación política. Así las cosas, y junto con el desarrollo histórico de la humanidad, el concepto es retomado por los renacentistas, quienes sin embargo, poco pudieron hacer contra el poder absoluto del monarca, que técnicamente eliminaba el clásico concepto de ciudadano 5 .

En los siglos posteriores al Renacimiento, la ciudadanía y el status de ciudadano clásico casi desapareció, aplastada por las teorías y burocracias del Estado centralizado y absoluto. El modelo político dominante en europa occidental fue la monarquía absoluta, en la cual, la conceptualización de ciudadanía y ciudadano estaba asociada a la idea de autogobierno, por lo que no hubo ya lugar, para el concepto grecorromano de ciudadanía.

Esta modificación del sentido de la ciudadanía, según Velasco, tiene que ver sobre todo con la consolidación del estado territorial moderno, caracterizado no solo por su amplia extensión, lo que dificulta la participación de una ciudadanía activa, sino por la concentración de poder en manos del príncipe/gobernante y el desarrollo consiguiente de la teoría de la

\footnotetext{
3 MIRALLES, Juan Antonio Horrach, "Sobre el concepto de ciudadanía: historia y modelos" en Factótum, vol. 6, 2009, p. 4

4 MIRALLES, Juan Antonio Horrach, "Sobre el concepto de ciudadanía..., op.cit., p. 6.

5 VELASCO, Juan Carlos, "Estado nacional y derechos de los inmigrantes: sobre la redefinición de la ciudadanía" en Arbor, vol. 181, no 713, 2005, p. 44.
} 
soberanía. El ciudadano viene a equipararse con el súbdito y el súbdito debe obediencia total hacia el príncipe soberano, no hay igualdad ni participación política. El soberano solo debe protección para sus súbditos. Esto favorece la aparición de una sociedad civil, separada del ámbito político ${ }^{6}$.

Esta evolución histórica del concepto de ciudadanía, también ha sugerido interpretaciones teóricas, que han ido de la mano con la teoría del estado moderno y el nacimiento de los estados-nación soberanos, brindando una nueva conceptualización al ciudadano, esta vez, ligada a la teoría del Contrato Social. En relación a esto último y según los postulados definidos por Tomas Hobbes, el ciudadano en el estado moderno, es definido como el titular o portador de ciertos derechos que el estado-nación está en la obligación de garantizar y proteger. En esa misma línea, el status de ciudadano, derivado de un contrato social, es la situación que nos diferencia del hombre en estado natural. Claramente, esta concepción está ligada fuertemente al debate kantiano-optimista en contraposición del hobbesiano-pesimista, y si bien, dichas conceptualizaciones son base de la ciencia política y del análisis socio-político occidental contemporáneo, con el desarrollo natural de las ciencias sociales y las reflexiones en torno al término, se han ido paulatinamente aumentando las dimensiones de esta conceptualización ${ }^{8}$. Por un lado, se han incluido derechos modernos a nivel constitucional, en gran parte de los catálogos constitucionales de derechos fundamentales de los estados- naciones occidentales, tales como la propiedad, la libertad de expresión, la libre asociación, la libertad de culto, etc.

De este modo también, y según Spinoza, "Ilamamos ciudadanos a los hombres que se considera que gozan de todas las ventajas que procura la ciudad en virtud del derecho civil"9. Dichas apreciaciones obedecen a la evolución del concepto, que se explican principalmente por una serie de cambios y transformaciones en las esferas sociales, políticas y económicas, en que ha sido testigo el estado-nación occidental, durante el pasado siglo XX.

El concepto de ciudadano, puede pensarse desde dos perspectivas, una que lo ve como poseedor de derechos y obligaciones, que es la visión más extendida, trabajada por Thomas Marshall, mientras que la otra visión, comprende al ciudadano como actor de una identidad cultural, en el sentido en que la ciudadanía involucra un sentimiento de pertenencia a una comunidad imaginada ${ }^{10}$. Estos cambios, imponen la constante redefinición de lo que es la ciudadanía, máxime si nos planteamos el importante papel que cumple la globalización en la relación del ciudadano con el estado-nacional que pertenece geográficamente ${ }^{11}$.

Como sabemos, el concepto de globalización trae directa relación con el de integración y cooperación, esto en virtud de las interacciones entre los diferentes actores de la sociedad

\footnotetext{
6 Ibídem.

7 HOBBES, Thomas, Leviatán o La materia, forma y poder de una república, eclesiástica y civil, Fondo de Cultura Económica, México D.F., 1994.

8 BARRERA, Claudia Sofía, "Hacia un nuevo concepto de ciudadanía global" en Revista Via Iuris, no 7, 2009, p. 99.

9 SPINOZA, Baruch, Tratado político (trad. y estudio preliminar de Enrique Tierno Galván), Tecnos, Madrid, 1996.

10 MARSHALL, Thomas, Citizenship and Social Class: And Other Essays, University Press, Cambridge, 1950.

${ }^{11}$ BARRERA, Claudia Sofía, "Hacia un nuevo concepto...", op.cit., p.100.
} 
internacional contemporánea. Solamente esta afirmación, es suficiente para plantearnos, si el actual concepto de ciudadanía, responde efectivamente a las nuevas exigencias políticas y sociales de un mundo globalizado. Por otro lado, el concepto de ciudadanía está ligado a un análisis imperativamente interno, como un asunto de las relaciones domésticas y jurídicas entre un individuo y el estado-nación al cual éste pertenece. Lo que complejiza su conceptualización. Pero, entender el concepto de ciudadanía y ampliarlo, es resultado de un análisis sistémico, que se basa en la concepción de un sistema supra-estatal de gobierno, dentro del cual la sociedad internacional y sus actores en constante interacción, desempeñan un papel fundamental. Según Barry Hindess, el gobierno de un estado, nunca es simplemente un asunto de relaciones internas entre el estado y sus propios ciudadanos o súbditos ${ }^{12}$.

También, es evidente el hecho, que estas nuevas relaciones estatales, propias de la época expansiva de las políticas neoliberales, han ayudado a extender el concepto de ciudadanía, incluso fomentando una instrumentalización del concepto, con el objetivo de unir su evolución a la par, con el fenómeno de la globalización. Así, podemos ver ejemplos de integración, como la Unión Europea (UE), la Unión de Naciones Suramericanas (UNASUR) o la Comunidad de Estados Latinoamericanos y Caribeños (CELAC), que tienen proyecciones interesantes de políticas, respecto a ciudadanías regionales, reconocimientos de documentos de identidad o participación en elecciones de cargos, como en el caso del Parlamento Europeo o el Parlamento Latinoamericano (Parlatino).

Sumemos también, lo planteado por Stephen Castles, al señalar que el aumento de las migraciones a nivel mundial, como fenómeno contemporáneo, es también un factor gravitante en la materialización y ejercicio de la ciudadanía global ${ }^{13}$. La migración internacional, ha resultado en la formación de relaciones que se extienden por casi todo el planeta, y como lo señala Fernando Ponce, cinco son los factores que fomentan y expresan este fenómeno. Primero, la extensión del mercado de bienes y servicios, que es el sentido más inmediato y no desprovisto de prejuicios que se da a este término. Segundo, la preponderancia que adquieren los organismos supranacionales de control y coordinación, como la Organización de las Naciones Unidas (ONU), la Organización Mundial del Comercio (OMC) o el Fondo Monetario Internacional (FMI). Tercero, la aceptación cada vez más grande de los derechos humanos como los parámetros éticos universales, que nos dicen qué es un trato humano y qué no lo es. Cuarto, el aumento y diversificación de los flujos migratorios del sur al norte. Los analistas de este fenómeno nos dicen que, en la última década, más personas se han instalado en más países del norte, que en cualquier otra región del globo ${ }^{14}$. Y por último, la formación de una

12 HINDESS, Barry, "La ciudadanía neoliberal" en Revista mexicana de ciencias políticas y sociales", vol. 45, n 186, 2002, p.123.

${ }^{13}$ CASTLES, Stephen, "Migración internacional a comienzos del siglo XXI: tendencias y problemas mundiales" en Revista Internacional de Ciencias Sociales, vol. 165, 2000, p. 19.

${ }^{14}$ Según el Reporte de Organización Mundial para las Migraciones de 2015, la tasa de migración neta (TMN) de los países del hemisferio norte, es decir los países con mayor Índice de Desarrollo Humano, supera en un 68\%, a la de los países del hemisferio sur. Estados Unidos, por ejemplo, en 2015, alcanzaba la cifra de 3,24 migrantes por 1000 habitantes, al igual que España, que para 2015, obtuvo una TMN que alcanzó los 7,24 migrantes por cada 1000 habitantes. En contraposición, Bolivia presenta en el mismo año una TMN del orden de -0.69 y el Congo de - 7,02. INTERNATIONAL ORGANIZATION FOR MIGRATION, Migrant Smuggling Data and Research: A global review of the emerging evidence base, Geneva, 2016: http://publications.iom.int/es/system/files/smuggling_ report.pdf [Consultado el 30 de enero de 2017]. 
especie de cultura mundial, al menos en sus expresiones ${ }^{15}$.

Entonces bien, y de acuerdo con Yasemin Soysal, este fenómeno está ligado a un movimiento transnacional del trabajo, de la educación, del turismo, etcétera, generando la necesidad de abandonar los residuos de un realismo político ortodoxo, y regular jurídicamente las relaciones entre el estado y el individuo no nacional. Aquel que conserva y transporta trasnacionalmente, algunos de los derechos y obligaciones que los estados han reconocido en la sociedad internacional ${ }^{16}$. Este ejercicio, da argumento a las afirmaciones expertas, de un aumento del uso y reconocimiento de la ciudadanía global y el ciudadano internacional. Pero, ¿qué entendemos hasta ahora por ciudadanía global? y ¿cómo han regulado los estados-nación esta tendencia en el actual orden mundial? Estos cuestionamientos, necesitan respuestas concretas y pertinentes, en virtud de un análisis profundo y vinculado a las causalidades intrínsecas del fenómeno migratorio internacional.

Pues bien, cuando nos referimos al concepto de ciudadanía global, aludimos a una nueva relación, enmarcada obviamente, en la todavía actual crisis del estado-nación, donde el individuo actual, ya no genera vínculos taxativos con un estado determinado ${ }^{17}$. Sino que, el proceso mundial vertiginoso de incorporación de nuevos actores y factores, como la apertura de los mercados, los tratados de libre comercio, los procesos tecnológicos, la creación de organismos de jurisdicción internacional, la globalización los mercados y la economía, entre otros, provocan una adaptación del ciudadano a esta realidad económica, que no puede ser menospreciada por los actuales estados-nación ${ }^{18}$. Por otro lado, algunos avances regulatorios aplicados por parte de organismos intergubernamentales, hacen que sea cuestionada la ciudadanía como concepto practico, no solo de hecho, sino de derecho, puesto que, el estado es incapaz de dar solución efectiva a los problemas surgidos de las fisuras en el ejercicio de la ciudadanía ${ }^{19}$.

Con respecto al origen de esta nueva forma de relación, Jordi Borja y Manuel Castell explican que;

"el control estatal sobre el espacio y el tiempo se ve superado cada vez más por los flujos globales de capital, bienes, servicios, tecnologías, comunicación y poder. La captura por parte del estado del tiempo histórico, mediante su apropiación de la tradición y la reconstrucción de la identidad nacional es desafiada por las identidades plurales definidas por los sujetos autónomos. El intento del estado de reafirmar su poder en el ámbito global, desarrollando instituciones supranacionales, socava aún más su soberanía. Y su esfuerzo por restaurar la legitimidad, descentralizando el poder administrativo regional y local, refuerza las tendencias centrifugas al acercar a los ciudadanos al

\footnotetext{
${ }^{15}$ PONCE, Fernando, "La ciudadanía en tiempos de migración y globalización: una aproximación desde la ética" en Revista Aportes Andinos, no 7, 2003, pp. 1-6

${ }^{16}$ SOYSAL, Yasemin, "Post national citizenship: Reconfiguring the familiar terrain" en NASH Kate y SCOTT, Alan, The Blackwell Companion to Political Sociology (eds.), Blackwell Publishing Ltd, Oxford, 2001, p. 337.

17 BARRERA, Claudia Sofía, "Hacia un nuevo concepto...", op. cit, p.103.

18 ROSERO, Acevedo Gloria, "Estado y Sociedad Civil" en Módulo de la Escuela de Liderazgo Democrático del Programa Ciudadanía y Desarrollo, Corporación Viva la Ciudadanía, 1994, p. 19.

${ }^{19}$ BARRERA, Claudia Sofía. "Hacia un nuevo concepto...", op.cit., p. 104.
} 
gobierno pero aumentando su desconfianza al estado-nación, tal como se creó en la edad moderna de la historia, parece estar perdiendo su poder, y esto es esencial, no su influencia"20.

Así las cosas, el estado-nación, según Sandro Mezzadra, ha entrado al proceso de globalización, comprometiendo en ello, varias de sus formas de hegemonía, algunas simplemente base de la sociedad moderna, como el control en la relación de los habitantes del territorio donde se ejerce la soberanía, la ciudadanía y la nacionalidad ${ }^{21}$. También, ha perdido terreno en medio del proceso de institucionalización neoliberal, fragmentando su soberanía, almacenándola en grandes procesos de integración y alianzas de seguridad, en el marco de la ya anunciada globalización, que según lo plantea Boaventura de Sousa, "es la intensificación de las relaciones sociales a nivel mundial que vincula localidades distintas, de la manera que los acontecimientos locales son modelados por eventos que tienen lugar a muchas millas de distancia y viceversa"22. Estas interrelaciones, comenzaron a gestarse inicialmente con el auge de las actividades económicas y políticas trasfronterizas, a las que luego se sumaron las actividades sociales, culturales, científicas, laborales, académicas, etc. Dando paso al componente primario de la ciudadanía global, el elemento cosmopolita.

El concepto de cosmopolita, ha sido desarrollado desde la antigüedad hasta la globalización del siglo XXI, y según lo explica Castany Prado, podemos distinguir cinco etapas en la historia del cosmopolitismo occidental. La primera sería la del cosmopolitismo clásico o aristocrático e incluiría movimientos como el cínico y el estoico, según los cuales los hombres están unidos por la razón universal o logos; la segunda, sería la del cosmopolitismo cristiano, que consideraría que todos los hombres son hermanos por ser hijos de un mismo Dios; la tercera, sería la del cosmopolitismo moderno o republicano, que consideraría que lo que nos une a todos es el ser sujetos de un jus natural de alcance universal; la cuarta, sería la del cosmopolitismo posmoderno/neoliberal, que consideraría que lo universal es el mercado y la comunidad de intereses; y la quinta, sería la del cosmopolitismo posnacional, que, en lo que respecta a occidente, trataría de recuperar los mejores aspectos del cosmopolitismo ilustrado $y$, en lo que respecta al resto del mundo, trataría de construir un cosmopolitismo global que no pueda ser acusado de euro céntrico ${ }^{23}$.

Ante esto, es importante observar que el cosmopolitismo posnacional, ha se ha ido generando fuertemente a través del desarrollo de la desterritorializacion del ciudadano ${ }^{24}$, que se hace más evidente cada día, ya que el ciudadano puede adquirir/ejercer derechos y contraer obligaciones al margen de su localización geográfica como producto, por ejemplo, del desarrollo tecnológico y de las comunicaciones, permitiendo las interacciones

${ }^{20}$ CASTELLS, Manuel y BORJA, Jordi, "Las ciudades como actores políticos" en Novos estudios CEBRAP, vol. 45, no julio, 1996, p. 335.

${ }^{21}$ MEZZADRA, Sandro, "The gaze of autonomy: capitalism, migration and social struggles" en SQUIRE Vicki, The Contested Politics of Mobility: Borderzones and Irregularity, Routledge, Londres, 2011, pp. 123-124.

22 DE SOUSA SANTOS, Boaventura, La globalización del derecho. Los nuevos caminos de la regulación y la emancipación, Universidad Nacional de Colombia - Facultad de Derecho, Ciencias Políticas y Sociales Instituto Latinoamericano de Servicios Legales Alternativos (ILSA), 1998, p. 288.

23 PRADO, Bernat Castany, "Apología del cosmopolitismo. Konvergencias" en Revista de Filosofía y Culturas en Diálogo, no 13, 2006, p. 3.

${ }^{24}$ ENTRENA, Francisco, Modernidad y cambio social en Trotta, Madrid, 2001, p. 254. 
entre personas de las más diversas y alejadas comunidades, formando comunidades o colectividades mundiales ${ }^{25}$. Así, el elemento explicativo, lo da el nacimiento de las relaciones supraterritoriales, multiculturales, multiétnicas que han dado paso, a un nuevo espacio social, donde se desarrolla la nueva ciudadanía. A su vez, esta organización autónoma de los individuos desterritorializados, provocada por la globalización y la pérdida del papel principal del estadonación, ha originado, un auge en la organización de la sociedad civil internacional, que actúa como respuesta y en contexto de los procesos globales contingentes. Las Organizaciones No Gubernamentales (ONG), así como los movimientos transnacionales culturales o ideológicos, son por su parte una manifestación evidente de este proceso de organización sin fronteras. Donde, el ciudadano, no está comprometido con un estado en particular, sino que su rol se modifica y su compromiso se afianza con la sociedad en su conjunto, entablando una relación universal a fin de adquirir el status de ciudadano global26.

Pero, este fenómeno de organización colectiva mundial y de avance en el concepto de ciudanía global, debe en gran parte su desarrollo, al fenómeno migratorio, como señalábamos previamente, puesto que el aumento cuantitativo de migraciones en el mundo, ha permitido generar un debate interesante respecto a las nuevas relaciones de estado/ciudadano. La Organización Internacional para las Migraciones (OMI) en 2013, señala que alrededor de 214 millones de personas, han o están migrando constantemente, constituyendo un $3,1 \%$ de la población mundial actual. Sin embargo, este proceso no es homogéneo, dado que las más altas tasas de migración se dan en países como Qatar con un 87\%, Emiratos Árabes Unidos con un $70 \%$, Jordania con un $46 \%$, Singapur con un $41 \%$ y Arabia Saudita con un $28,6 \%$, en contraposición con países como Sudáfrica con un 3,7\% o India con un $0,4 \%{ }^{27}$. Aunque el panorama respecto a las migraciones es diverso, podemos afirmar que el simple hecho que, una de cada treinta y cinco personas en el mundo es migrante, nos da una clara idea, de lo importante de una regulación ad hoc, respecto al concepto de ciudadano, ya que su papel ya no se remite a su relación con el país de origen, sino que ha su relación con los estados receptores que deben lidiar con un alto número de extranjeros, y en diferentes grados de organización dentro de los territorios soberanos.

La fundamentación de este proceso migratorio, viene dado por la búsqueda de seguridad política, jurídica y social, además del aumento de la calidad de vida, así también, la mundialización de los mercados, juega un papel importante a la hora de buscar mejores oportunidades a nivel personal, y explican también esta movilidad humana. A su vez, la paulatina formación de redes de migrantes de una región específica, se ha convertido en una fuerza dominante para mejorar la movilidad de las personas. Influyen en las decisiones políticas de los países de acogida, de prestar asistencia económica a los países de origen. También influyen en las relaciones económicas y comerciales entre el país de origen y el país de destino, y requieren procesos de integración más creativos y productivos. Los avances en el transporte y en las tecnologías de la comunicación, que vinculan lugares y personas a nivel mundial, conducen al surgimiento de

25 BOBBIO, Norberto y BOVERO, Michelangelo, Teoría general de la política, Trotta, Madrid, 2003.

${ }^{26}$ APPADURAI, Arjun, "La globalización y la imaginación en la investigación" en Revista Internacional de Ciencias Sociales, vol. 160, 1999.

27 INFORME DE LA ORGANIZACIÓN MUNDIAL PARA LA MIGRACIÓN, 2013: http://www.oim.org.co/sobremigracion/2-uncategorised/2445-licitacion-416-de-2012-cm-205-fabricacion-suministro-y-transporte-demobiliario-escolar.html [Consultado el 3 de agosto de 2016]. 
un espacio de migración transnacional. Este cubre más de un espacio geográfico, en el cual los migrantes pueden trasladarse de un hogar a otro. Aparte del movimiento físico, el flujo de información, competencias y remesas son los demás componentes del espacio migratorio transnacional. Las brechas entre el espacio geográfico y el espacio migratorio han disminuido, lo cual tiene serias consecuencias en la migración internacional ${ }^{28}$. Una de ellas, es que pocos países tienen una política migratoria bien definida y articulada. Resulta difícil encauzar algo, si no existe una estructura política para guiar a los gestores. No obstante, aun los países que sí cuentan con una política migratoria bien respaldada por su legislación, experimentan serias dificultades en materia de gestión migratoria 29 .

Algunos críticos de las políticas públicas, particularmente en los países desarrollados, han caracterizado el periodo comprendido entre mediados de los años setenta y la actualidad como un cuarto de siglo de mala gestión migratoria ${ }^{30}$. Más aún, el movimiento de personas a gran escala no ha cesado. La migración irregular se ha convertido en uno de los problemas más acuciantes de nuestro tiempo. Al respecto Stephen Castles, señala que el tráfico de migrantes actualmente se equipara al narcotráfico, como una de las fuentes más importantes de ingresos respecto al crimen organizado. La trata de personas, se ha vuelto una preocupación importante a nivel mundial. La migración, ha escalado puestos en la lista de problemas cruciales que los países del mundo desarrollado deben afrontar y ahora ocupan el primer lugar en la agenda política de los países del G8 ${ }^{31}$.

Finalmente, toda esta movilidad humana, gestiona y sirve de precursor en la organización de la sociedad civil internacional, que funciona de catalizador de los intereses comunes trasfronterizos, que los estados, algunos aún en un realismo político, no son capaces de comprender, viéndose sobrepasados, enfrentando el fenómeno como un problema y no como un resultado empírico de la globalización. Permitiendo de esta manera, una acción más efectiva por parte de la propia sociedad civil internacional, que da un ejemplo global de gobernabilidad y organización civil.

\section{Migración, exclusión/inclusión y ciudadanía.}

Las migraciones de carácter internacional, se ligan estrechamente con los conceptos de exclusión e inclusión, apropósito del modelo de desigualdad social imperante, donde los movimientos humanos trasnacionales que se han desarrollado sin interrupción desde la segunda guerra mundial, sobre todo en los años setenta, han abarcado a todas las áreas geográficas del globo. Cualesquiera que sean las intenciones que motivan los movimientos humanos, estas en gran parte terminan agrupando a las familias, generando colectividades y grupos étnicos, asentados en estados receptores, y que terminan modificado su estructura social y cultural interna 32 .

\footnotetext{
${ }^{28}$ Ibídem.

${ }^{29}$ Ibíd.

${ }^{30}$ APPADURAI, Arjun, "La globalización y la imaginación...", op. cit, p. 54.

${ }^{31}$ CASTLES, Sthephen, "Migración irregular: causas, tipos y dimensiones regionales" en Migración y desarrollo, vol. 8, no 15, 2010, pp. 50-56.

32 CASTLES, Stephen, "Globalización y migración: algunas contradicciones urgentes", Discurso inaugural presentado en la reunión del Consejo Intergubernamental del MOST/UNESCO, 1997, p. 98.
} 
El concepto de exclusión, a la luz del fenómeno migratorio se puede entender, según lo expresa Joan Subirats, como un proceso de alejamiento progresivo de una situación de integración social, en el que pueden distinguirse diversos estadios en función de la intensidad, desde la precariedad o vulnerabilidad más leve hasta las situaciones de exclusión más graves $^{33}$. A su vez, el concepto de inclusión, lo ha definido y explicado este autor, a partir de dos pasos fundamentales, el primero dice Subirats, se da por el acceso efectivo y garantizado a la ciudadanía y a los derechos económicos, políticos y sociales correspondientes a la misma, así como posibilidades de participación efectiva en la esfera política. El segundo, en cambio pasaría por la conexión y solides de las redes de reciprocidad social, ya sean estas de carácter efectivo, familiar, vecinal, comunitario o de otro tipo ${ }^{34}$.

Los conceptos de exclusión e inclusión han sido efectivamente puestos en contradicción por Stephen Castles, quien escribió, apropósito del fenómeno migratorio en un contexto de política económica neoliberal, que este proceso, que incluye a algunos y excluye a otros es, aparentemente, el resultado de fuerzas anónimas del mercado. Por lo tanto, ni los individuos, ni las instituciones ni el estado, asumen responsabilidad alguna por esta evolución, que podría arrastrar a millones de personas a la pobreza. El triunfo del mercado, tanto a nivel nacional como internacional, significa que muchos gobernantes ya no ven las grandes desigualdades como un problema, sino como algo esencial para la eficacia del sistema económico ${ }^{35}$. Adosando así, estos conceptos al de desigualdad social.

En los países de migrantes, los núcleos familiares y los grupos étnicos experimentan cambios importantes y prolongados. La migración es un aspecto de la disolución de las estructuras económicas y sociales tradicionales que ha producido la globalización ${ }^{36}$. En algunos países como Italia, se logró experimentar una cultura de migración ${ }^{37}$. Aunque la percepción del migrante se ha orientado hacia la idea de la exclusión, ya sea económica o social, puesto que, como lo señala Castles, "numerosos emigrantes se ven obligados a abandonar sus países, porque ya no queda lugar para ellos. Incluso pueden llegar a verse como excluidos de la comunidad nacional"38.

Por otro lado, en los estados-nación receptores de migrantes, las comunidades locales, también experimentan grandes transformaciones con la incorporación de colectividades étnicas foráneas. Estos cambios van desde la modificación de las estructuras productivas y la división del trabajo, hasta un replanteamiento de valores sociales y culturales. Dichos cambios, también repercuten en el concepto de exclusión, puesto que en ocasiones los migrantes se ven discriminados culturalmente o desadaptados por las desventajas económicas del entorno. Desventajas propias de los países que aún no han regulado eficientemente, problemas como

\footnotetext{
33 GUILLÉN, Eva Alfama e I PINEDA, Anna Obradors, "Ciudadanía e inclusión social frente a las inseguridades contemporáneas. La significación del empleo" en Documentos de trabajo (Fundación Carolina), no 32, 2009, p. 133.

${ }^{34}$ GUILLÉN, Eva Alfama e I PINEDA, Anna Obradors, "Ciudadanía e inclusión social frent...", op.cit., pp. $135-136$.

35 CASTLES, Stephen, "Globalización y migración...", op.cit., p. 97.

${ }^{36}$ Ibídem, p.97.

37 CROLLA, Adriana Cristina, "iPuro gringo! Perfiles de la inmigración italiana en las colonias santafesinas" en Zibaldone. Estudios italianos, vol. 3, no 1, 2015, pp. 140-141.

${ }^{38}$ CASTLES, Stephen, "Globalización y migración: algunas contradicciones...", op.cit., p.3.
} 
la subcontratación y la ausencia de derechos civiles ${ }^{39}$.

Este proceso, no deja fuera el problema de la ciudadanía, previamente explicado, puesto que el solo hecho de regenerar los espacios demográficos de los estados-nación, exige imperantemente el surgimiento de ciertas regulaciones a nivel jurídico interno de cada estado. Por ello, algunos darán un tratamiento similar o diferente al concepto de ciudadanía y a las normas de otorgación de esta ciudadanía. En este aspecto, es importante mencionar el surgimiento de las ciudadanías múltiples y su reconocimiento. Según la OMI, una gran cantidad de personas posee ciudadanías múltiples, aunque históricamente algunos estados se han sentido incómodos, solo con el concepto de ciudadanía doble, los factores de la globalización han contribuido en la generación de una apertura evidente en este aspecto. Existe una importante presión, derivada de las propias interacciones de la economía mundial y el clima político exterior, para que los estados-nación den cabida a estos modelos de ciudadanía ${ }^{40}$.

En el área jurídica y legalista del actuar de los estados, algunos han posibilitado el desarrollo y mantenimiento de ciudadanías dobles y múltiples ${ }^{41}$. El derecho internacional, no restringe ni limita a los estados a adoptar medidas y legislar abiertamente, en su derecho interno, estas cuestiones. Algunos estados, restringen a través de sus constituciones, la adquisición o pérdida de la ciudadanía, solo por la adquisición de otra, dando a elegir. Otros, siguen la Declaración Universal de Derechos Humanos, que estipula que nadie puede perder la nacionalidad por acto arbitrario ${ }^{42}$.

En cuanto a la práctica de los estados receptores de inmigrantes, que tiene en su ordenamiento interno una regulación que les permite obtener derechos políticos, luego de un par de requisitos generales, veremos que existe una nueva relación ciudadano/estado, toda vez que, es más numerosa la lista de personas con ciudadanía múltiple, que han logrado comprometer jurídicamente a dos o más estados, que por motivos diplomáticos o simples controversias que son acogidas en la Corte Internacional de Justicia, originando disputas internacionales como resultado de derechos y obligaciones reclamadas. Una regla tradicional del derecho consuetudinario internacional, apoyado en el Artículo 4 de la Convención de La Haya de 1930, establece que un estado puede no ofrecer la protección diplomática a uno de sus nacionales contra un estado cuya nacionalidad también posee la persona en cuestión.

Esta regla, permanece aún en la práctica de los Estados, aunque se ha reducido gradualmente su importancia debido a una serie de excepciones. Una de estas excepciones, se relaciona con el aumento de demandas en el caso de los crímenes de lesa humanidad ${ }^{43}$, aunque el desarrollo de los derechos humanos no considera obsoleta la institución de

${ }^{39}$ ROCHA ROMERO, David, "Migrantes precarios. Inmigrantes mexicanos en la subcontratación en Estados Unidos" en Norteamérica, vol. 6, no 1, 2011, pp. 100-106.

${ }^{40}$ INFORME 3.7. Organización Internacional para las Migraciones. Migración y ciudadanía: http://www.crmsv.org/ documentos/IOM_EMM_Es/v3/V3S07_CM.pdf [Consultado el 23 de septiembre de 2016].

${ }^{41}$ ARROYO, Juan Carlos Velasco, "Transnacionalismo migratorio y ciudadanía en mutación" en Claves de razón práctica, no 197, 2009, p. 35.

42 Declaración Universal de los Derechos Humanos. Asamblea General de las Naciones Unidas, París, 1948: http:// www.un.org/es/universal-declaration-human-rights/

43 DI BERNARDI, Guillermo, et al., Derechos Humanos y Ciudadanía, Santillana Perspectivas, Buenos Aires, 2007. 
protección diplomática de un estado a favor de sus ciudadanos.

Volviendo, a la situación demográfica y la movilidad humana contemporánea, ya señalamos que este proceso deriva principalmente de la globalización, y que la sumatoria de todos los elementos de esta globalización, ponen a sangrar, aun más las heridas del estadonación. De esta forma, los estados-nación se enfrentan cada vez más, al desafío de desarrollar un sentido de cohesión y unión nacional, en un contexto de diversidad transnacional étnica y cultural. Los debates internos a nivel político, se tornan hacia la adquisición y pérdida de la ciudadanía. Surgen, a partir de la notoriedad de la modificación social producto de los inmigrantes, sus familiares inmediatos y sus descendientes, formando importantes colectividades, como sucede en el sur de Estados Unidos. Como resultado, se vuelven menos claras las distinciones entre jus soli y jus sanguinis ${ }^{44}$.

Por su parte, la Convención Europea sobre Nacionalidad (CEN), sugiere que es papel del derecho internacional, abordar el problema de la naturalización de los extranjeros que residen de manera habitual y legal dentro del territorio de un estado miembro ${ }^{45}$. En la mayoría de los países miembros de la Unión Europea, mantienen normas comunes de 5 a 10 años de residencia para la obtención de derechos políticos; ciudadanía y nacionalidad ${ }^{46}$. Y otros, mantienen como criterios excluyentes y tradicionales, accesos tales como la descendencia. Los procesos, de obtención de ciudadanías, varían en cada país o región. Esto nos refuerza la idea de la dicotomía entre exclusión y migración, como bien lo explica Oscar Gómez, al señalar que;

"Los migrantes tienen que batallar para no ser explotados, discriminados, ni victimizados por redes criminales, o por la intolerancia o la violencia xenófoba; el camino de la aceptación está lleno de múltiples obstáculos, es un viaje sin muchas alternativas: triunfas o pierdes. 'Triunfas' a un costo enorme en todos los aspectos de la vida, donde las privaciones y las restricciones de todo orden se imponen con el propósito de ser aceptado e 'integrado'; o 'pierdes' al ser expulsado, deportado o 'retornado de manera voluntaria', al no lograr la adaptación, o el 'reconocimiento' para sentirse ciudadano de esa otra sociedad a la cual viajó con tantas ilusiones y esfuerzos" ${ }^{\prime 47}$.

Así las cosas, es un hecho que mientras los estados-nación no son homogéneos en sus políticas respecto a las normas internacionales, el proceso se ralentiza. Con los actuales hechos de terrorismo en Francia y en otras zonas de Europa y Medio Oriente. La exclusión y discriminación producida y fomentada por algunos estadistas y sociedades nacionales, sobre el problema migratorio actual, ha generado que dicho proceso sea visto negativamente, al respecto, Martínez de Pinzón, señala;

"Hoy por hoy, las migraciones son descritas y analizadas como un problema que

${ }^{44}$ VELASCO, Juan Carlos, "Estado nacional y derechos...", op.cit., p. 45.

${ }^{45}$ CONVENCIÓN EUROPEA SOBRE NACIONALIDAD: http://www.coe.int/en/web/conventions/full-list/-/ conventions/treaty/166 [Consultado el 2 de octubre de 2016].

${ }^{46}$ Comision Europea para las Migraciones: http://ec.europa.eu/immigration/instancias-y-funciones/masinformacion/explicar-las-normas-por-que-hay-normas-de-la-ue-y-normas-nacionales_es\#EUImmRuless [Consultado el 23 de octubre de 2016].

47 GOMEZ, Oscar, Migración, Derechos, Ciudadanía y Bienestar, 1er Congreso Nacional de Ciencias Políticas, Universidad de los Andes Bogotá, octubre 1-3 de 2008. 
afecta a la seguridad de los Estados y de ahí que las respuestas lo sean también en clave policial. La inmigración, los inmigrantes son vistos como un peligro que atenta al orden y al bienestar de las sociedades desarrolladas, en lugar de una oportunidad más. Los gobernantes, los representantes empresariales y los medios de comunicación no hacen nada más que propagar este sencillo mensaje, así como promover medidas de corte penal y policial sin entrar a analizar las causas más profundas, ni a esbozar respuestas más complejas"48.

Es claro, que los migrante, actores relevantes en la agenda internacional, aún están ligados a experiencias de exclusión en el proceso globalizado de movilidad humana. Las trasformaciones sociales, las políticas de los estados y el aumento de procesos de interacción, forman parte de algunas contradicciones que enfrenta el actual orden mundial.

Existe una clara tendencia, hacia una mayor tolerancia de la ciudadanía múltiple. Una gran cantidad de estados han cambiado su legislación, con el fin de aceptar la ciudadanía múltiple para ciertas categorías de inmigrantes, tomando en cuenta, por tanto, las relaciones de un inmigrante con su país de origen. A su vez, la mundialización de los mercados, ha provocado reacciones de migrantes, dado y en busca de las nuevas oportunidades, y relaciones laborales en el actual proceso de globalización ${ }^{49}$. Los problemas son variados, desde la homogenización del derecho interno y el internacional, hasta aquellos que respectan a la exclusión social y sus derivados en las políticas domésticas de los estados- nación. Sumados, por cierto, a los dispares procesos de obtención y reconocimiento de las ciudadanías múltiples. Aquello, nos da un pequeño esquema de la situación actual y exige la necesidad de replantearnos el concepto de ciudadanía, bajo las nuevas experiencias de los estados-nación y sus relaciones con y entre la sociedad civil internacional y el fenómeno migratorio.

A esto último, debemos agregar algunos ejemplos de experiencias de ciudadanías locales, en torno a la inclusión de los migrantes, pues como vimos, la exclusión está presente en el desarrollo del proceso migratorio, como un lastre que ralentiza dicha evolución. La inclusión, se ve ligada directamente con el concepto de integración, observada en sus dos niveles básicos; a nivel estatal o supraestatal y a nivel socio-cultural. Es decir, una dimensión política y una dimensión más profunda, ligada a la identidad cultural. Al respecto, Ricardo Zapata-Barrero señala que;

"la inclusión puede ser vista como acceso a derechos por parte de las personas (la población inmigrante) que carecen de los mismos derechos que los ciudadanos, o bien como equiparación real de las personas que teniendo los mismos derechos, encuentran dificultades para ponerlos en práctica por razones de sexo, color de la piel, cultura, religión, y en general, por factores que no dependen de la voluntad de la persona sino que son propiedades de nacimiento"50.

Entonces, podemos afirmar que la inclusión es un proceso que requiere previamente

48 MARTINEZ de PISÓN, José, ¿Tienen derechos los inmigrantes? Derechos humanos y procesos migratorios: paradojas y posibilidades, Universidad de Valencia, Jornadas sobre los inmigrantes como nuevos actores del desarrollo, Globalización, migración y derechos, 2004.

49 QUIJANO, Aníbal, "Colonialidad del poder, globalización y democracia" en Utopías, nuestra bandera: revista de debate político, no 188, 2001, pp. 97-123.

${ }^{50}$ BARRERO, Ricard Zapata, Multiculturalidad e inmigración, Síntesis, Madrid, 2004, p. 207. 
de una situación diferente a la que permite acceder a todas las áreas de una sociedad. Se trata de un proceso de adecuación del inmigrante a la sociedad receptora, que necesita que ésta, adquiera los modos de vida y se enriquezca con la cultura y las costumbres de la colectividad que la acoge, y viceversa, dejando de lado la rigidez de los suyos, eliminando así, su condición de extraño o diferente. Es de esta forma, según Osuna et al., "es que la sociedad de adopción le reconocerá como uno de los suyos, produciéndose así la plena integración del inmigrante"

Esta integración, se desarrolla en tres niveles, según Felipe Aliaga, en primer lugar, el nivel de inclusión en los sistemas funcionales básicos de la sociedad receptora, donde el inmigrante inicia su relación jurídica, al ingresar al país, y su relación funcional con el sistema burocrático y los servicios básicos, vivienda, educación, salud, trabajo, etc. En este nivel de inclusión, el migrante, se organiza e interactúa a nivel institucional, es reconocido. Un segundo nivel, la relación con el surgimiento de un complejo esquema comprensivo entre los mismos individuos, dando paso a un nuevo sistema de socialización, factorizada por las constantes interacciones cotidianas, entre los inmigrantes y los autóctonos. Y un tercer nivel, caracterizado por la adaptación de los artefactos, la técnica y los procesos, en este nivel, el cambio social, se ha manifestado impactando diferentes y variadas esferas de la vida, de la economía o la política. En este nivel las tradiciones, se modifican se unen y transforman, los servicios se expanden y se especifican e individualizan, se regula en torno al migrante, se reconoce e incluye. Este nivel, opera mayormente en el plano sistémico, sin embargo, se aprovecha del nivel fenomenológico para obtener información, por ejemplo: los bancos con planes de inversión para personas inmigrantes, o los supermercados que incluyen productos de distintas procedencias ${ }^{52}$.

En definitiva, el proceso de inclusión, acarrea diversas consecuencias, los resultados dependerán del grado de desarrollo del país receptor, como también del elemento cultural predomínate del estado receptor. El análisis, lo podemos extender y conectar, con el avance en esta materia y el crecimiento de la sociedad civil internacional. Pues, siguiendo la idea que, si un estado-nación evoluciona hacia el concepto de ciudadanía múltiple, permitiendo y facilitando el proceso de canalización de la inmigración, pueden estos últimos, ser capaces en derecho y acceder a organizarse internamente y realizar tareas comunes transnacionalmente 0 bien, pueden adherir de pleno derecho, a Organizaciones No Gubernamentales, preexistentes. Así, de esta forma, la sociedad civil, se integra y organiza en virtud de intereses comunes y trasnacionales, generando con ello una nueva dimensión de la sociedad y la cooperación, utilizando los canales de la globalización. Se organizan al punto de competir con los estadosnación, en temáticas de interés nacional y mundial, participando activamente en las Organizaciones Internacionales Gubernamentales, y otros tantos foros internacionales.

En América latina, la agenda regional esta activamente constituida por la organización civil internacional, trabajando como punto de fuga, el proceso migratorio interregional. Diferentes organizaciones desarrollan actividades, a nivel nacional, regional y global, y

51 OSUNA, Álvaro Retortillo, et al., "Inmigración y modelos de integración: entre la asimilación y el multiculturalismo" en Revista universitaria deficiencias del trabajo, vol. 7, 2006, p.125.

52 SÁEZ, Felipe Andrés, "El imaginario social en torno a la integración de los inmigrantes en España" en Revista de investigación multidisciplinar, no 4, 2012, p. 22. 
encuentros paralelos a los oficiales, a su vez que, son invitados como observadores a los encuentros anuales coordinados por los estados latinoamericanos, en conjunto con la OIM o la Secretaría General Iberoamericana (SEGIB), como también, en espacios de integración subregional, tales como la Comunidad de Estados Latinoamericanos y Caribeños (CELAC) y la Unión de Naciones Suramericanas (UNASUR) ${ }^{53}$.

Es importante profundizar un poco más, sobre el papel de la sociedad civil internacional y su relación con la migración. Veamos primero, la conceptualización que se ha realizado sobre la sociedad civil y posteriormente el papel jugado por esta a nivel internacional, en relación al incentivo de políticas públicas para enfrentar de mejor manera el proceso migratorio.

\section{La sociedad civil internacional; migraciones a la luz de una voluntad integradora.}

El concepto de sociedad civil, es usualmente definido en forma negativa, es decir se explica a través de lo que no es, y no por lo que realmente es. Como argumenta Norbert Lechner, se trata de un término bastante ambiguo, con distintas connotaciones y con un carácter polémico, que sirve más que nada para señalar una problemática. Efectivamente la ambivalencia del término explica su eficacia política, pues permite invocarla sin precisar qué es exactamente la sociedad civil ${ }^{54}$. Otra versión, un poco más clásica es la de Michael Walzer, que la entiende como "un espacio de asociación humana sin coerción, más el conjunto de la trama de relaciones que llena ese espacio"55. Es decir, la sociedad civil nace de la necesidad de interacción.

Por otro lado, Jürgen Habermas, desarrolla el concepto, más orientado hacia la política internacional, siguiendo sus ideas, la sociedad civil cumple un rol trascendental en el espacio público-político. Habermas, define a la sociedad civil como el conjunto de asociaciones y organizaciones voluntarias, no estatales y no económicas, que surgen de forma más o menos espontanea, y que arraigan las estructuras comunicativas de la opinión pública en el mundo de la vida, ya que recogen las resonancias de los problemas de la vida privada y elevándoles la voz los trasmiten al espacio de la opinión pública política. Son ciudadanos organizados, que desde la vida privada, buscan interpretaciones públicas para sus intereses y que influyen en la formación institucionalizada de la opinión y voluntad política ${ }^{56}$.

Las nociones más comunes para nombrar a la organización de la sociedad civil, la definen como no gubernamentales y sin fines de lucro. En ese sentido sus objetivos, interesan o deberían interesar a alguna otra gente además de sus miembros, en ese sentido podrían decirse que son públicas. A estas organizaciones, se entra y se sale voluntariamente y se autogobiernan ${ }^{57}$. En este grupo reina la heterogeneidad respecto al origen de sus miembros, además, muchas nacen de la mano con la llegada de migrantes, que forman colectividades

${ }^{53}$ DOMENECH, Eduardo, "La ciudadanización de la política migratoria en la región sudamericana: vicisitudes de la agenda global" en NOVICK Susana (Comp.), Las Migraciones en América Latina, Catálogos, Buenos Aires, 2008.

${ }^{54}$ LECHNER, Norbert. "La (problemática) invocación de la sociedad civil" en Revista Perfiles Latinoamericanos, vol. 3, n० 5,1994, p. 142.

55 WALZER, Michael (ed.), Toward a global civil society, Berghahn Books, 1995.

56 HABERMAS, Jürgen, et al. Facticidad y validez: sobre el derecho y el Estado democrático de derecho en términos de teoría del discurso, Trotta, Madrid, 1998.

57 LEIRAS, Marcelo, La incidencia de las organizaciones de la sociedad civil en las políticas públicas. Definiciones, explicaciones y evaluaciones de las literaturas especializadas local e internacional, Siglo XXI, 2007, p. 19. 
y luego se organizan y asocian para velar por la continuidad del proceso migratorio al alero del respeto a los derechos humanos. Acá se entremezclan, los conceptos de inclusión e integración.

La sociedad civil, se organiza y asocia transfronterizamente, preocupándose eminentemente por el proceso migratorio. El mundo que conforman actualmente las asociaciones de migrantes, las organizaciones no gubernamentales, las pastorales migratorias y otros grupos que hoy se entienden como sociedad civil, tiene como común denominador el concepto de solidaridad internacional ${ }^{58}$.

En cuanto a la incidencia política de las organizaciones de la sociedad civil en la definición de políticas públicas y lineamientos migratorios, no todas las organizaciones tienen como objetivo involucrase en las discusiones sobre las políticas que afectan a los colectivos que defienden. Una primera distinción, podría ser sugerida, solo por el hecho de las motivaciones de las organizaciones, unas querrán aplicarse directamente, en la sociabilización y otras, a través de la política. Estas últimas, alterando el curso de la política nacional e internacional. En este sentido, resulta útil observar la metodología que es frecuente para que una organización de la sociedad civil, que aplica en la dimensión política presionando para la conformación de políticas públicas migratorias, u de otra naturaleza, pero siempre de interés común o colectivo. En esto, debemos tener claro, que el ámbito de incidencia de una organización de la sociedad civil, está dado por el rol jugado en la elaboración de agenda pública.

En este sentido, podemos identificar, en primer lugar, las diferentes acciones de elaboración de información, sobre la cuestión migratoria, que surgen desde la sociedad civil, fundamentalmente, a partir del análisis y la investigación realizada por los numerosos centros de estudios, que se enfocan en recopilar experiencias e interpretar las numerosas dimensiones que abarca la problemática en cuestión, ya sean la migración, la feminización de los flujos migratorios, la inserción socioeconómica, la problemática de la dicotomía inclusión/exclusión, el acceso a derechos político, como la ciudadanía, entre otros temas relacionados ${ }^{59}$. A partir de estas acciones, surge el debate académico y político, se imprimen libros y se organizan congresos que ponen el tema en la agenda de discusión de la sociedad ${ }^{60}$. El segundo paso, es el momento de la definición de la política a ejecutar. La sociedad civil puede contribuir directamente, ya sea participando en el proceso de debate de la generación política o presentando alternativas no habituales. Conocidos son los casos de leyes promulgadas, donde la iniciativa surgió de un movimiento social respaldado por organizaciones civiles. Esto se genera, a través de la participación sistemática en foros o consejos consultivos organizados por organismos estatales. Donde el resultado exitoso, variara según el grado de participación real de la sociedad civil ${ }^{61}$. Un tercer paso, es la implantación y ejecución de la política escogida y apoyada, donde se establece con qué medios y quiénes serán los responsables de llevar adelante el programa migratorio ${ }^{62}$. Aquí, veremos, como el estado-nación comparte con la

${ }^{58}$ CHIARELLO, Leonir Mario (ed.), Las políticas públicas sobre migraciones y la sociedad civil en América Latina. Los casos de Bolivia, Chile, Paraguay y Perú, Scalabrini International Migration Network, Nueva York, 2013.

${ }^{59}$ Ibídem, p. 57.

60 Ibíd., p. 57.

${ }^{61}$ CHIARELLO, Leonir Mario (ed.), Las políticas públicas sobre migraciones...op.cit., p. 58.

${ }^{62}$ En este aspecto, importante es el caso argentino, en materia de incidencia en la política migratoria, a través 
sociedad civil la implementación de ciertas tareas específicas que influyen directamente con el éxito o fracaso de los programas. Un último paso, es el de monitoreo. La sociedad civil, independientemente de si participa o no, fiscalizara al estado por el incumplimiento de las políticas ligadas a sus intereses y que se han hecho públicos ${ }^{63}$.

Como podemos observar, la incidencia de la sociedad civil, en el problema migratorio y otros tantos intereses comunes, es un hecho. Su conceptualización, nos ayuda a comprender los procesos actuales de la globalización, pero sobre todo nos involucra más al concepto cultural e intangible del ciudadano global. Este, que se manifiesta en la organización civil transfronteriza y coadyuva al estado a sostener en un marco respetuoso de los derechos humanos, el proceso migratorio.

En fin, las variedad y multiplicidad de organizaciones no gubernamentales, centros de estudios, asociaciones de migrantes, y pastorales migratorias que se encuentran trabajando hoy en día, son extremadamente vastas y heterogéneas. Demostrando su importancia y su rol, en contener las problemáticas del proceso de globalización, respecto a las migraciones. Son parte de un proceso de inclusión, y juegan un rol fundamental también a nivel político exterior, dado su función en la opinión pública internacional.

Bien, pero no solo la sociedad civil se relaciona con la migración, por ser este último uno de los temas centrales en la agenda internacional, sino que también, por su composición, dado el alto grado de relación entre migrantes y formación de organizaciones no gubernamentales. Al respecto, Jonathan Fox y William Gois, han planteado una explicación con respecto al desarrollo de una sociedad civil migrante. Su explicación viene dada por el establecimiento de diez tesis, que dan cuenta del carácter de la sociedad civil migrante, las nuevas relaciones con el estado-nación, y demás actores sociales y políticos. El concepto de sociedad civil migrante, es el punto base para las propuestas de Fox y Gois, que son explicadas, a la luz de la evolución histórica de estas formas de organización. Plantean, en la primera tesis; que las organizaciones que constituyen la sociedad civil migrante se basan en múltiples identidades colectivas, a menudo superpuestas. En la segunda tesis; que en la constitución de las formas de organización social de los migrantes intervienen, de un lado, estos mismos y del otro, su entorno político institucional, así como la disponibilidad de aliados no migrantes en el país huésped. En la tercera tesis; que las agendas basadas en los derechos dependen del marco de los derechos humanos de las Naciones Unidas, el cual se ha construido con el consenso de la comunidad internacional. En la cuarta tesis; que para equilibrar las diferencias entre, por un lado, la labor de servicio y de defensoría y por el otro, la labor dedicada a la formulación de políticas de defensoría, que es más estratégica, hay que realizar intercambios continuos y divisar estrategias deliberadas. En la quinta tesis; que las campañas para establecer acuerdos internacionales sobre derechos pueden motivar y sostener coaliciones transfronterizas de la sociedad civil y difundir los enfoques basados en derechos a sectores más amplios y diversos de la ciudadanía. En la sexta tesis; que

\footnotetext{
de la conformación de la Mesa de organizaciones en defensa de los derechos de los migrantes, en 1996. Esta Organización reunía a distintas organizaciones civiles cuyo principal objetivo era la derogación de la ley Videla de migraciones. Las reuniones sostenidas junto al congreso nacional fueron la base de la reforma migratoria de 2003.

${ }^{63}$ CHIARELLO, Leonir Mario (ed.), "Las políticas públicas...", op.cit., p. 60.
} 
las organizaciones de migrantes a menudo se conjuntan como redes, pero sólo algunas redes pueden sostener coaliciones. En la séptima tesis; que la construcción de coaliciones de la sociedad civil que buscan conjuntar a organizaciones de países tanto emisores como receptores de migrantes requiere una estrategia deliberada y una inversión continua. En la octava tesis; que los migrantes organizados en distintos escenarios buscan la representación y la rendición de cuentas mediante distintos repertorios y múltiples canales. En la novena tesis; que la participación de migrantes en proyectos de desarrollo en sus países de origen puede ser muy importante en términos de infraestructura social, pero presenta dificultades a la hora de generar empleo que evite nuevas migraciones. Y última tesis; que la dinámica de una coalición cuyo compromiso consiste en realizar campañas a favor de los derechos de los migrantes es muy diferente a la de una coalición cuyo compromiso consiste en abordar cuestiones de desarrollo y las causas estructurales de la migración ${ }^{64}$.

Estas tesis, nos permiten realizar un análisis más general y a la vez particularizado del fenómeno de la migración y la sociedad civil organizada en dicho proceso. Por ende, es recomendable que se reconozca seriamente, el papel genuino de la sociedad civil migratoria en los procesos migratorios internacionales. A su vez, es recomendable que tanto el país receptor como el emisor, reconozcan la experiencia de los migrantes, más allá de los derechos humanos, sino también en su poder multicultural de organización. Además, es indispensable movilizar recursos estatales y supraestatales, para dinamizar y ayudar a las organizaciones de migrantes, así como a las instituciones, a fin de que puedan gestar programas de capacitación, que permitan una inclusión social más equitativa. Otra recomendación, va por el lado del reconocimiento y valoración por parte de los estados-nación, de las alianzas y movimientos transfronterizos. Incentivando el pluralismo, la inclusión e integración cultural.

En definitiva, el desarrollo de la sociedad civil internacional, ha estado marcado por el desarrollo conjunto de una sociedad civil migrante, que tiene que lidiar con el proceso de inclusión y los terrores de la exclusión, una sociedad civil migrantes, que es capaz de generar los lazos de confianza y participación, de tal envergadura que le permiten a los migrantes tener una voz unificadora a nivel trasfronterizo. Que a su vez, logra generar perspectivas de políticas públicas enmarcadas en las coyunturas más importantes de la agenda internacional y nacional. Como también, ser capaz de instalarse como un referente social-político capaz de fiscalizar al estado-nación en el cumplimiento de compromisos migratorios, entre otros temas.

\section{Conclusión}

Hemos hecho un recorrido analítico, sobre los conceptos de ciudadanía, ciudadano global, globalización, migraciones y sociedad civil. Nuestro análisis, no se acota a una región en especial, puesto que hoy en día, los análisis son hechos en un marco de un alcance global, siendo muy difícil aislar, los contenidos, ya que el proceso globalizador, se ha introducido en las mayor parte de las problemáticas desde una perspectiva sistémica.

A nivel internacional, el concepto de ciudadanía global, está en proceso de construcción,

\footnotetext{
${ }^{64}$ FOX, Jonathan y GOIS, William, "La sociedad civil migrante: diez tesis para el debate. Migración y desarrollo", vol. 8, n० 15, 2010, p. 92: http://www.scielo.org.mx/scielo.php?script=sci_arttext\&pid=S1870 $75992010000200003 \& \mathrm{In}$ $\mathrm{g}=\mathrm{es} \&$ tIng $=\mathrm{es}$ [Consultado el 01 de noviembre de 2016].
} 
aun es evidente observar países reticentes a la tendencia de la ciudadanía múltiple, propuesta en los foros internacionales por la sociedad civil internacional. Su desarrollo, está garantizado por el cumulo de acciones que se llevan a cabo a nivel intergubernamental, quienes debido a la mundialización de los mercados y los flujos económicos de producción, hacen necesario regular los derechos políticos del ciudadano desterritorializado. Por otro lado, los avances en materia de reconociendo jurídico de los derechos trasfronterizos que movilizan los migrantes, uno de los tantos efectos de la acelerada globalización, han generado preocupación en la sociedad internacional, al punto de incluir el fenómeno migratorio, como tema central en innumerables plataformas y foros internacionales. No solo la crisis del estado-nación, sino que también la crisis de la democracias como sistema político, han provocado un cambio en la naturaleza del concepto primitivo de ciudadanía, puesto que las modificaciones dimensionales del ciudadano han cambiado, al tiempo que se han generado otras, que comprometen un nuevo concepto de ciudadanía. La política neoliberal del actual sistema, ha generado rupturas profundas en las relaciones estado/ciudadano, al punto que los individuos, ya no generan lazos importantes con el estado, sino que sobresalen los lazos intangibles y trasfronterizos, motivados por la migración y la organización de la sociedad civil internacional. Esta última, que identifica a los individuos bajo el ejercicio de una ciudadana global responsable y participativa, inclusiva en su naturaleza, y solidaria en su actuar. La sociedad civil internacional, rompe con la cadena tradicional de problematización de la sociedad, se hace cargo de los temas de su propia naturaleza; como loes el fenómeno migratorio.

Por otro lado, estos conceptos se unen, a la luz de una sociedad, que exige una reconstrucción del estado-nación. Un reconocimiento de una sociedad internacional, donde actores como la sociedad civil internacional, juegan un papel clave a la hora de pronunciarse respecto a problemas globales. La injerencia de la sociedad civil, en el escenario internacional, ha generado abiertas reflexiones sobre la necesidad de regular el espacio geopolítico y con él, el de las migraciones. Las sociedades civiles migrantes, también son un ejemplo de estas nuevas relaciones entre el estado y el ciudadano actual, dado que el estado-nación ha tenido que modificar sus procedimientos, para escuchar y dialogar con migrantes empoderados y que trasportan trasfronterizamente derechos reconocidos universalmente, y que son protegidos y garantizados mundialmente. Además, es la propia sociedad civil quien maneja la opinión pública internacional, generando variaciones en los programas nacionales y mundiales, poniendo de manifiesto una importante injerencia de estas organizaciones en la agenda internacional.

Finalmente, hacer mención al proceso de crisis institucional y representacional del neoliberalismo político globalizado, sus políticas han modificado las relaciones ciudadano/estado/ migrante, puesto que la evolución de la globalización hacia una gobernanza global, requieren con urgencia, una deconstrucción del concepto de ciudadano, y de la metodología política de participación, donde se superpongan la integración y la colaboración. La dicotomía de inclusión/ exclusión, presente en los procesos de adaptación de migrantes en una sociedad, debe ser eliminada. La exclusión solo fisura los estados-nación, los hace más débiles institucionalmente. En el modelo globalizado de política y organización civil actual, el estado debe abrirse y expandirse, a través de la inclusión y del concepto de ciudadanía global al futuro del mundo, con pasos firmes e inclusivos, en virtud de un beneficio objetivo a la humanidad. 


\section{Bibliografía}

AGUILÓ, Antoni Jesús, "Globalización neoliberal, ciudadanía y democracia. Reflexiones críticas desde la teoría política de Boaventura de Sousa Santos" en Revista Crítica de Ciencias Sociales y Jurídicas, vol. 20, no 4, 2008.

APPADURAI, Arjun, "La globalización y la imaginación en la investigación" en Revista Internacional de Ciencias Sociales, vol. 160, 1999.

ARROYO, Juan Carlos Velasco, "Transnacionalismo migratorio y ciudadanía en mutación" en Claves de razón práctica, nº 197, 2009.

BARRERA, Claudia Sofía, "Hacia un nuevo concepto de ciudadanía global" en Revista Via Iuris, no 7 , 2009.

BARRERO, Ricard Zapata, Multiculturalidad e inmigración, Síntesis, Madrid, 2004.

BOBBIO, Norberto y BOVERO, Michelangelo, Teoría general de la política, Trotta, Madrid, 2003.

CASTELLS, Manuel y BORJA, Jordi, "Las ciudades como actores políticos" en Novos estudios CEBRAP, vol. 45, no julio, 1996.

CASTLES, Stephen, "Globalización y migración: algunas contradicciones urgentes", Discurso inaugural presentado en la reunión del Consejo Intergubernamental del MOST/UNESCO, 1997.

CASTLES, Stephen, "Migración internacional a comienzos del siglo XXI: tendencias y problemas mundiales" en Revista Internacional de Ciencias Sociales, vol. 165, 2000.

CASTLES, Sthephen, "Migración irregular: causas, tipos y dimensiones regionales" en Migración y desarrollo, vol. 8, no 15, 2010.

CHIARELLO, Leonir Mario (ed.), Las políticas públicas sobre migraciones y la sociedad civil en América Latina. Los casos de Bolivia, Chile, Paraguay y Perú, Scalabrini International Migration Network, Nueva York, 2013.

COMISION EUROPEA PARA LAS MIGRACIONES. Disponible en http://ec.europa.eu/immigration/ instancias-y-funciones/mas-informacion/explicar-las-normas-por-que-hay-normas-de-la-ue-ynormas-nacionales_es\#EUImmRuless [Consultado el 23 de octubre de 2016].

CONVENCIÓN EUROPEA SOBRE NACIONALIDAD. Disponible en http://www.coe.int/en/web/conventions/ full-list/-/conventions/treaty/166 [Consultado el 2 de octubre de 2016].

CROLLA, Adriana Cristina, "iPuro gringo! Perfiles de la inmigración italiana en las colonias santafesinas" en Zibaldone. Estudios italianos, vol. 3, no 1, 2015.

DE SOUSA SANTOS, Boaventura, La globalización del derecho. Los nuevos caminos de la regulación y la emancipación, Universidad Nacional de Colombia - Facultad de Derecho, Ciencias Políticas y Sociales Instituto Latinoamericano de Servicios Legales Alternativos (ILSA), 1998.

Declaración Universal de los Derechos Humanos. Asamblea General de las Naciones Unidas, París, 1948. Disponible en http://www.un.org/es/universal-declaration-human-rights/ [Consultado el 30 de Enero de 2017].

DI BERNARDI, Guillermo, et al., Derechos Humanos y Ciudadanía, Santillana Perspectivas, Buenos Aires, 2007.

DOMENECH, Eduardo, "La ciudadanización de la política migratoria en la región sudamericana: vicisitudes de la agenda global" en NOVICK Susana (Comp.), Las Migraciones en América Latina, Catálogos, Buenos Aires, 2008.

ENTRENA, Francisco, Modernidad y cambio social en Trotta, Madrid, 2001.

FOX, Jonathan y GOIS, William, "La sociedad civil migrante: diez tesis para el debate. Migración y desarrollo", vol. 8, no 15, 2010. Disponible en http://www.scielo.org.mx/scielo.php?script=sci_ arttext\&pid=S1870 75992010000200003\&lng=es\&tIng=es [Consultado el 01 de noviembre de 2016]. 
GOMEZ, Oscar, Migración, Derechos, Ciudadanía y Bienestar, 1er Congreso Nacional de Ciencias Políticas, Universidad de los Andes Bogotá, octubre 1-3 de 2008.

GUILLÉN, Eva Alfama e I PINEDA, Anna Obradors, "Ciudadanía e inclusión social frente a las inseguridades contemporáneas. La significación del empleo" en Documentos de trabajo, no 32 Fundación Carolina, 2009.

HABERMAS, Jürgen, et al. Facticidad y validez: sobre el derecho y el Estado democrático de derecho en términos de teoría del discurso, Trotta, Madrid, 1998.

HINDESS, Barry, "La ciudadanía neoliberal" en Revista mexicana de ciencias políticas y sociales, vol. 45, no 186, 2002.

HOBBES, Thomas, Leviatán o La materia, forma y poder de una república, eclesiástica y civil, Fondo de Cultura Económica, México D.F., 1994.

INFORME 3.7. Organización Internacional para las Migraciones. Migración y ciudadanía: http://www. crmsv.org/documentos/IOM_EMM_Es/v3/V3S07_CM.pdf [Consultado el 23 de septiembre de 2016].

INFORME DE LA ORGANIZACIÓN MUNDIAL PARA LA MIGRACIÓN, 2013. Disponible en http://www.oim. org.co/sobre-migracion/2-uncategorised/2445-licitacion-416-de-2012-cm-205-fabricacionsuministro-y-transporte-de-mobiliario-escolar.html [Consultado el 3 de agosto de 2016].

INTERNATIONAL ORGANIZATION FOR MIGRATION, Migrant Smuggling Data and Research: A global review of the emerging evidence base, Geneva, 2016. Disponible en http://publications.iom. int/es/system/files/smuggling_report.pdf [Consultado el 30 de Enero de 2017].

LAVOLPE, Francisco, "Las nuevas ciudadanías de la globalización" en Hologramática, vol. 8, n 6, 2008.

LECHNER, Norbert. "La (problemática) invocación de la sociedad civil" en Revista Perfiles Latinoamericanos, vol. 3, no 5, 1994.

LEIRAS, Marcelo, La incidencia de las organizaciones de la sociedad civil en las políticas públicas. Definiciones, explicaciones y evaluaciones de las literaturas especializadas local e internacional, Siglo XXI, México DF, 2007.

MARSHALL, Thomas, Citizenship and Social Class: And Other Essays, Cambridge University Press, Cambridge, 1950.

MARTINEZ de PISÓN, José, ¿Tienen derechos los inmigrantes? Derechos humanos y procesos migratorios: paradojas y posibilidades, Universidad de Valencia, Jornadas sobre los inmigrantes como nuevos actores del desarrollo, Globalización, migración y derechos, 2004.

MEZZADRA, Sandro, "The gaze of autonomy: capitalism, migration and social struggles" en SQUIRE Vicki, The Contested Politics of Mobility: Borderzones and Irregularity, Routledge, Londres, 2011.

MIRALLES, Juan Antonio Horrach, "Sobre el concepto de ciudadanía: historia y modelos" en Factótum, vol. 6, 2009.

OSUNA, Álvaro Retortillo, et al., "Inmigración y modelos de integración: entre la asimilación y el multiculturalismo" en Revista universitaria deficiencias del trabajo, vol. 7, 2006.

PONCE, Fernando, "La ciudadanía en tiempos de migración y globalización: una aproximación desde la ética" en Revista Aportes Andinos, no 7, 2003.

PRADO, Bernat Castany, "Apología del cosmopolitismo. Konvergencias" en Revista de Filosofía y Culturas en Diálogo, no 13, 2006.

QUIJANO, Aníbal, "Colonialidad del poder, globalización y democracia" en Utopías, nuestra bandera: revista de debate político, no 188, 2001.

ROCHA ROMERO, David, "Migrantes precarios. Inmigrantes mexicanos en la subcontratación en Estados Unidos" en Norteamérica, vol. 6, no 1, 2011. 
SÁEZ, Felipe Andrés, "El imaginario social en torno a la integración de los inmigrantes en España" en Revista de investigación multidisciplinar, no 4, 2012.

ROSERO, Acevedo Gloria, "Estado y Sociedad Civil" en Módulo de la Escuela de Liderazgo Democrático del Programa Ciudadanía y Desarrollo, Corporación Viva la Ciudadanía, 1994.

SOYSAL, Yasemin, "Post national citizenship: Reconfiguring the familiar terrain" en NASH Kate y SCOTT, Alan (eds.), The Blackwell Companion to Political Sociology, Blackwell Publishing Ltd, Oxford, 2001.

SPINOZA, Baruch, Tratado político (trad. y estudio preliminar de Enrique Tierno Galván), Tecnos, Madrid, 1996.

VELASCO, Juan Carlos, "Estado nacional y derechos de los inmigrantes: sobre la redefinición de la ciudadanía" en Arbor, vol. 181, no 713, 2005.

WALZER, Michael (ed.), Toward a global civil society, Berghahn Books, 1995. 


\section{RELACIONES INTERNACIONALES}

Revista académica cuatrimestral de publicación electrónica Grupo de Estudios de Relaciones Internacionales (GERI) Universidad Autónoma de Madrid, España

www.relacionesinternacionales.info

ISSN 1699 - 3950

ff facebook.com/RelacionesInternacionales

twitter.com/RRInternacional 